\title{
Inmunopatología del dengue: importancia y participación de los monocitos y sus subpoblaciones
}

\author{
Juan Sebastián Naranjo-Gómez', Jorge Andrés Castillo-Ramírez², Paula Andrea Velilla- Hernández², \\ Diana María Castaño-Monsalve ${ }^{1}$
}

\section{RESUMEN}

El dengue es una infección viral aguda transmitida por la picadura de mosquitos del género Aedes, la cual produce hasta 100 millones de infecciones anuales en el mundo. Una gran proporción de individuos infectados con el virus presentan infecciones asintomáticas. Sin embargo, de los individuos que desarrollan la enfermedad, el $95 \%$ presentan siognos y síntomas similares a una virosis común, que por lo general se autoresuelven (dengue con y sin signos de alarma). El $5 \%$ restante puede evolucionar a manifestaciones graves, caracterizadas por hemorragias, daño orgánico, choque hipovolémico e incluso la muerte (dengue grave).

Los monocitos son uno de los blancos principales de la infección producida por el virus del dengue (DENV), los cuales participan en la replicación del mismo y en la producción de una gran variedad de citoquinas que contribuyen con el daño de diferentes tejidos y órganos en respuesta a la infección. Los monocitos se dividen en tres subpoblaciones: clásica (CD14++CD16-), no clásica (CD14+CD16++) e intermedia (CD14++CD16+), las cuales poseen respuestas funcionales contrastantes en diferentes procesos inflamatorios, en cuanto a la producción de mediadores solubles e interacción con el endotelio. Los monocitos no clásicos parecen ser los principales productores de mediadores inflamatorios como el TNF- $\alpha$ y la IL- $1 \beta$ en respuesta a la infección por DENV. Por lo tanto, se propone que cada subpoblación de monocitos debe tener un papel diferencial en la inmunopatología de la enfermedad.

En esta revisión se recopilan los principales aspectos de la replicación viral y la inmunopatología del dengue, así como los principales hallazgos referentes al papel de los monocitos en esta infección y además, se propone un papel potencial y diferencial de las subpoblaciones de monocitos.

1 Grupo de Inmunología Celular e Inmunogenética (GICIG). Instituto de Investigaciones Médicas, Facultad de Medicina, Universidad de Antioquia UdeA, Calle 70 No 52-51, Medellín, Colombia.

2 Grupo de Inmunovirología. Departamento de Microbiología y Parasitología, Facultad de Medicina, Universidad de Antioquia UdeA, Calle 70 No 52-51, Medellín, Colombia.

Correspondencia: Diana María Castaño Monsalve; diana.castano@udea.edu.co

Recibido: febrero 5 de 2018

Aceptado: junio 8 de 2018

Cómo citar: Naranjo-Gómez JS, Castillo-Ramírez JA, Velilla-Hernández PA, Castano-Monsalve DM. Inmunopatología del dengue: importancia y participación de los monocitos y sus subpoblaciones. latreia. 2019 Jul-Sep; 32(3):204-216. DOI 10.17533/udea.iatreia.09. 


\section{PALABRAS CLAVE}

Dengue; Dengue Grave; Monocitos

\section{SUMMARY}

\section{Dengue immunopathology: Importance and participation of monocytes and their subsets}

Dengue is an acute viral infection transmitted by the bite of the mosquito belonging to the genus Aedes, which produce until 100 millions of infections worldwide per year. A high proportion of infected individuals develop an asyntomatic infection. Nevertheless, among patients that develop a clinical disease, $95 \%$ of them show clinical signs and symptoms similar to common virosis, that in the most of the cases can recover by themselves (dengue with and without alarm sions); the remaining $5 \%$ can evolve to severe manifestations, characterized for hemorrhages, organic damage, hypovolemic shock and death (severe dengue).

Monocytes are one of the main targets of the infection by dengue virus (DENV), supporting the viral replication, contributing to the production of high levels of cytokine and the damage of different tissues and organs in response to the infection. Monocytes are divided in 3 subsets: classical (CD14++CD16-), non-classical $(\mathrm{CD} 14+\mathrm{CD} 16++)$ and intermediate $(\mathrm{CD} 14++\mathrm{CD} 16+)$; which have differential functional responses in the inflammatory process, regarding the production of inflammatory mediators and the interaction with the endothelium. The non-classic monocytes seem to be the main producers of inflammatory mediators such as TNF- $\alpha$ and IL- $1 \beta$ in response to DENV infection. Therefore, it is proposed that each monocyte subset may have a different role in the disease immunopathology.

This review collect the main evidence regarding the viral replication and the immunopathology of dengue, also it shows the most important findings about the role of monocytes in this infection and proposes a potential differential involvement of monocytes subsets.

\section{KEYWORDS}

Dengue; Severe Dengue; Monocytes

\section{EPIDEMIOLOGÍA}

EI dengue es una enfermedad infecciosa causada por un virus que recibe el mismo nombre (DENV) $(1,2)$, del cual, se han identificado a la fecha cuatro serotipos: DENV-1, DENV-2, DENV-3 y DENV-4 (3). Recientemente se propuso la existencia del DENV-5 (4); sin embargo, es importante aclarar que todavía se considera un hallazgo controversial. Este virus es transmitido por mosquitos del genero Aedes, principalmente Ae. aegyptiy $A$ e. albopictus (5). La localización geográfica del DENV depende directamente de la ecología y la distribución de sus vectores, siendo las zonas tropicales y subtropicales las más afectadas por esta enfermedad (6).

Según la OMS, el número de casos de dengue ha aumentado hasta 30 veces en los últimos 50 años en el mundo (5), produciendo aproximadamente 96 millones de infecciones anuales (5, 7-10). Este incremento en los casos se debe a varios factores, entre ellos al aumento de la temperatura del planeta $y$ a una distribución más amplia de los vectores $(6,9)$. Dentro de las zonas de más alta incidencia del dengue se encuentran las regiones del sudeste de Asia, el Pacífico occidental, el Cono Sur de América, la Región Andina y Centroamérica (5). Actualmente, el continente americano contribuye con el $14 \%$ de los casos mundiales reportados, que corresponde entre 9 a 18 millones de las infecciones anuales. Esto provoca una alta carga económica sobre los servicios de salud en esta región, cuyos gastos ascienden aproximadamente a 2,1 billones de dólares estadounidenses anuales, superando los costos de otras enfermedades virales $(8,10)$.

Los únicos países que presentan los cuatro serotipos del virus dengue en Suramérica son Colombia, Venezuela y Perú, siendo Colombia quien ha reportado más muertes por esta causa (5).

Según el Instituto Nacional de Salud de Colombia, la incidencia de esta enfermedad ha ido en aumento en la última década (11). El informe epidemiológico realizado a finales del 2017 indicó una incidencia de 92,7 casos por cada 100.000 habitantes, con un total de 26.279 casos reportados para ese año, de los cuales el $1,1 \%$ correspondieron a dengue grave (11). 


\section{GENERALIDADES Y REPLICACIÓN DEL VIRUS DENGUE}

El dengue es un virus envuelto perteneciente a la familia Flaviviridae, cuyos serotipos varían del 25 al 40 $\%$ en su secuencia de aminoácidos y además se divide en genotipos que divergen aproximadamente en el 3 $\%$ de su secuencia (12). Los viriones del DENV son estructuras de $50 \mathrm{~nm}$ de diámetro que están compuestas por tres proteínas estructurales: cápside $(\mathrm{C})$, premembrana (PrM) o membrana (M) y envoltura (E) (9, 12-14). Varias copias de la proteína $C$ encapsulan el genoma (ARN) de polaridad positiva de 10,7 kb, formando una envoltura de simetría icosaédrica, la cual está cubierta por una bicapa lipídica derivada de la célula del hospedero, que contiene aproximadamente 180 copias de las proteínas M y E (13).

Este virus ingresa al ser humano por vía cutánea a través de la picadura de un mosquito hembra infectado, interactuando, inicialmente, con las células residentes de la dermis, especialmente las dendríticas y los macrófagos (15) (Figura 1).

El reconocimiento de las proteínas de la envoltura viral por los receptores presentes en estas células blanco, conlleva a su infección (Figura 1). Entre estos receptores tenemos el del lipopolisacárido (CD14), el de manosa (CD206), la molécula de adhesión de las células dendríticas DC-SIGN (CD209) y las proteínas de choque térmico HSP90/HSP70 ancladas a la membrana plasmática, entre otros (16). Este proceso de reconocimiento lleva principalmente a una endocitosis del virus mediada por clatrina (16). Adicionalmente, se ha descrito una vía de endocitosis que depende de anticuerpos denominada ADE (del inglés antibody-dependent enhancement), mediada por receptores para la fracción cristalizable $(\mathrm{Fc})$ de las Iog $(\mathrm{F} c \gamma \mathrm{R})$, la cual se ha asociado con el desarrollo de manifestaciones graves de la enfermedad. Esta vía de inorreso ocurre principalmente en infecciones secundarias con un serotipo distinto al inicial, en las cuales los anticuerpos que se producen $y$ recubren las partículas virales son subneutralizantes (17).

Posterior a la internalización y formación del endosoma, ocurren cambios conformacionales en la proteína viral E por la reducción del pH (18), que conducen a la fusión de la envoltura viral con la membrana endosomal y a la formación de un poro que libera el ARN viral al citoplasma (19). El ARN viral liberado va al retículo endoplasmático, donde ocurre la traducción a poliproteína y una segmentación en tres proteínas estructurales: C, M, E, y otras siete proteínas no estructurales (NS1, NS2a, NS2b, NS3, NS4a, NS4b, NS5).

La proteína E tiene varias funciones como la unión a receptores de lectina tipo $C$, heparán sulfato y $C D 14$ $(12,16,20,21)$, que permiten la internalización del virus; esta proteína también media la fusión del virión con la membrana del endosoma en células blanco. La proteína $M$ interactúa con la proteína $\mathrm{E}$, permitiendo la estabilidad de esta última y su respectiva interacción con los receptores mencionados $(22,23)$. Las proteínas NS participan en la replicación viral (24) y en la patogénesis de la enfermedad (22); por ejemplo, la NS5 es una metiltransferasa que sirve como ARN polimerasa dependiente de ARN (25-27).

La NS1 se considera un patrón molecular asociado a patógenos (28), que es reconocido por el TLR-4 (del inglés toll like receptor-4); esto último se ha demostrado en estudios in vitro, en los cuales se obervó un aumento en la expresión del ARN mensajero de citoquinas, como IL-6 y el TNF- $\alpha$ en CMSP (células mononucleares de sangre periférica) humanas y macrófagos de ratones expuestos a la proteína NS1, proceso que fue revertido con el uso de un anticuerpo antagonista contra el TLR-4 (28).

El ensamblaje de los viriones ocurre en el retículo endoplásmico por la interacción de las proteínas C con el ARN de polaridad positiva, sintetizado para formar la nucleocápside (24). La maduración del virión se da en la red Trans-Golgi, dependiente del pH y de las proteasas furinas, las cuales escinden el factor Pr de la proteína $M$, permitiendo su correcta interacción con la proteína E; esto le da la simetría icosaédrica al virus (12). Posterior a esta maduración, se libera el DENV al medio extracelular mediante exocitosis, sin que se altere la integridad celular, al tiempo que permite que la célula infectada continúe produciendo más viriones.

\section{INMUNOPATOLOGÍA DEL DENGUE}

Se ha propuesto que el DENV interactúa en la dermis, inicialmente con células residentes como las dendríticas, macrófagos tisulares y mastocitos $(29,30)$ (Figura 1), con las dos primeras como los blancos principales del virus $(31,32)$. Sin embargo, se ha demostrado que posteriormente el virus infecta células que han 
sido reclutadas a la dermis como monocitos y células dendríticas derivadas de monocitos (moDCs) (33). Las células infectadas, especialmente las dendríticas, miogran a los nódulos linfáticos regionales para realizar la presentación antigénica y así activar la respuesta inmune adaptativa (Figura 1); se cree que de esta forma el virus alcanza estos tejidos y una vez allí, los macrófagos y los monocitos reclutados son a su vez infectados por DENV (3). Como resultado de esta primera viremia, la infección se amplifica y el virus se disemina por el sistema linfático, llegando posteriormente a sangre periférica y a distintos órganos, en los cuales infecta células como monocitos (Figura 1), células dendríticas (34), hepatocitos (35), células endoteliales (36), macrófagos esplénicos y células de Kupffer $(37,38)$. Todo esto ocurre durante los tres primeros días del inicio de los síntomas, en los cuales se reportan los picos de la viremia en la sangre periférica (5).

Adicionalmente, los fagocitos mononucleares que entran en contacto con el virus pueden promover una respuesta para eliminar la infección, mediante el reconocimiento del DENV por receptores intracelulares como el TLR-3 que reconoce el ARN viral de doble cadena que se forma cuando DENV está en el proceso de replicación (39); también estarían los TLR-7 y TLR-8 que reconocen ARN de cadena sencilla, $y$ los sensores citoplasmáticos como la proteína inducible por ácido retinoico (RIG-I) y la proteína de diferenciación asociada al melanoma (MDA-5), que también reconocen ARN de doble cadena (12, 20, 40).

Estos receptores conducen a la activación de los factores reguladores del interferón (IRF) 3 y 7 , que inducen la producción de interferones tipo uno (IFN-I) (Figura 1), los cuales tienen una alta actividad antiviral intrínseca $(12,20)$ que se asocia con una resolución de la infección sin manifestaciones graves de la enfermedad (41). Además, se promueve la vía del factor nuclear kappa B $(\mathrm{NF}-\kappa \mathrm{B})$ y la producción de citoquinas proinflamatorias como el TNF- $\alpha$ e IL- $6, y$ de quimioquinas como CCL5 y CXCL12 (40). Estos factores solubles permiten la activación de otras células, como las endoteliales y mastocitos, las cuales amplifican la respuesta mediante la liberación de más mediadores solubles, mencionados previamente, al igual que otros promotores de inflamación como los derivados lipídicos (42).

Las infecciones por DENV generalmente se autoresuelven rápidamente. Estas se manifiestan con fiebre, mialgia, dolor muscular generalizado, vómito, dolor retroocular, entre otros síntomas. Se presentan entre los 4-10 días posteriores a la inoculación del virus. Sin embargo, menos del $5 \%$ de los casos pasan a ser dengue grave, caracterizado por un aumento en la permeabilidad vascular que lleva a la pérdida de plasma sanguíneo y la hemoconcentración. Generalmente está acompañado de una caída en el número de plaquetas y de una acumulación de líquidos en la región pleural o peritoneal, además, se pueden presentar cuadros de hemorragia grave y, en algunos casos, insuficiencia multiorgánica que puede causar la muerte del individuo si no es tratada a tiempo (5).

\section{DENGUE GRAVE}

Aún no son claras las causas por las cuales algunas personas desarrollan dengue grave, pero se ha propuesto que gran parte del desarrollo de esas manifestaciones está determinado por la interacción del virus con diversos componentes del sistema inmune del hospedero (9).

Dentro de los elementos del sistema inmune que se han asociado con el desarrollo de gravedad se han propuesto el ADE, basados en la premisa de que la mayoría de los casos de dengue grave ocurren en una infección secundaria tanto de niños como adultos (17). Este fenómeno se ha validado in vitro mediante el uso de sueros en pacientes que cursaron una infección secundaria por DENV en una línea celular de fibroblastos de ratón (BHK-21), que expresaron o no el FcyR.

Se observó que los anticuerpos subneutralizantes existentes en el suero, aumentaron la infección de las células que exprensaban el Fc $\gamma \mathrm{R}$ al compararse con las células de control (43). Resultados concordantes se han encontrado in vivo en el que ratones AG129 fueron inoculados intraperitonealmente con el suero de ratones sanos o de ratones infectados previamente con DENV-1.

Después de 24 horas los ratones fueron retados con DENV-2, se encontró que los animales expuestos a los sueros de los ratones infectados murieron a causa de la infección, mientras que los animales de control no lo hicieron. Estas y otras evidencias sugieren que el ADE puede estar aportando no solo al aumento de la infección de células blanco, sino también al desarroIlo de la gravedad en los pacientes con dengue (44). 
Por otro lado, la tormenta de citoquinas es uno de los fenómenos más importantes y ampliamente asociados con la agudización de la enfermedad. Se ha propuesto que se presenta cuando hay una carga viral inicial alta, junto con la activación de un gran número de células como monocitos, macrófagos, mastocitos y los linfocitos T, lo que lleva a un incremento en los niveles circulantes de citoquinas como TNF- $\alpha$, IL$1 \beta$, IL-2, IL-6, IL-8, IL-10, IFN- $\gamma$, entre otras (45-48) (Figura 1). Este incremento en las citoquinas séricas por DENV se ha evidenciado in vivo (49) y una asociación entre la presencia de estos mediadores y el compromiso tisular se ha desmotrado in vitro. Por ejemplo, se ha observado que el TNF- $\alpha$ o sueros de pacientes infectados tienen un efecto directo sobre las monocapas de las células endoteliales, disminuyendo así la expresión de las proteínas de la unión intercelular como la cadherina-VE (50) y ZO-1 (51), lo que lleva a la pérdida de la integridad endotelial. Además de estos factores, también se ha propuesto que los mediadores lipídicos y las aminas vasoactivas pueden aportar al daño endotelial directo, ya que factores como el activador de plaquetas (PAF) reducen la expresión de ZO-1 en células endoteliales (52), así como inducen el NF-кB, que a su vez conduce a la producción de las citoquinas citadas previamente $(53,54)$.

A pesar de esto, es importante mencionar que existen evidencias contradictorias referentes a las citoquinas plasmáticas y a los niveles de las mismas en los pacientes con dengue $(51,55)$. Aún no existe un consenso sobre los factores inmunológicos y no inmunológicos que están llevando a los pacientes a desarrollar dengue grave.

\section{PAPEL DE LOS MONOCITOS Y SUS SUBPOBLACIONES EN LA INFECCIÓN POR DENV}

Los fagocitos mononucleares representan un subgrupo de leucocitos de origen mieloide, son descritos como una población que circula en la sangre en forma de monocitos y que pueden poblar los tejidos como macrófagos (56). Cabe resaltar que la mayoría de los autores también incluyen a las células dendríticas dentro de este sistema celular (56). Los monocitos maduran a partir de células madre mielomonocíticas presentes en la medula ósea, pasan a la circulación sanguínea y de allí a colonizar los tejidos, al parecer, principalmente en respuesta a un estímulo exógeno o durante un proceso inflamatorio (57). Sin embargo, en los últimos años se ha demostrado que en un estado de reposo pueden existir reservas de monocitos en los tejidos del bazo, pulmón y piel, que cumplen funciones de patrullaje, donde posteriormente pueden migrar a nódulos linfáticos y presentar antígenos a los linfocitos T $(58,59)$.

En el contexto de la infección por DENV se ha observado que los monocitos son las células que permiten una mayor infección y replicación viral en la sangre periférica (60-62) (Figura 1). Esto se ha demostrado en modelos in vitro de infección por DENV, en los cuales CMSP infectadas con el serotipo 2 con una multiplicidad de infección (MOI) de cinco, tuøieron un mayor porcentaje de células positivas para la proteína viral E en los monocitos CD14+ (con un 4,34\%), al compararse con los linfocitos CD3 + y CD19+ (del 0,02 \% y 0,4\%, respectivamente) (60). Algo análogo se observó en pacientes con dengue durante la etapa febril de la enfermedad, en los cuales se encontró que los monocitos fueron las principales CMSP positivas para el antígeno viral PrM (61).

Un patrón semejante se ha observado ex vivo en niños menores de 14 años infectados con DENV, en los cuales se ha encontrado un mayor porcentaje de células positivas y una intensidad media de fluorescencia aumentada para la proteína viral PrM en los monocitos (63).

Además de ser uno de los principales blancos de la infección, los monocitos también se activan y responden al DENV mediante el reconocimiento del ARN viral por medio de los receptores TLR-7, TLR-8, RIG-1 y MDA-5, previamente mencionados (12, 20), lo que lleva a la producción de IFN-I y de citoquinas proinflamatorias como el TNF- $\alpha$, IL-1 $\beta$, IL-6 e IL-8, por monocitos humanos infectados in vitro con DENV-2 (64-66) (Figura 1). Este aumento en la producción de citoquinas por parte de los monocitos tambien se ha observado ex vivo en niños infectados con dengue, en los cuales se observó un aumento en el porcentaje de monocitos productores de TNF- $\alpha$ e IL- 6 al compararse con los controles sanos (67). Esto podría estar contribuyendo con la tormenta de citoquinas y las alteraciones en la permeabilidad vascular vistas en pacientes infectados con DENV (68).

La activación de monocitos se ha observado en pacientes con dengue, en los cuales se encuentra un 
aumento en el porcentaje de estos fagocitos que expresan ICAM-1 (molécula de adhesión intercelular), TLR-2 y TLR-4 al ser comparados con controles sanos (69); una inducción similar en la expresión de TLR2 se observa al infectar in vitro monocitos humanos con DENV-2 (69). Otro estudio también reportó un perfil activado $(C D 32+, C D 86+, C D 11 \mathrm{C}+)$ de los monocitos $\mathrm{CD} 14^{+}$en pacientes con dengue (61). Así mismo, el estado activado de los monocitos durante la infección se ha corroborado por el aumento en la expresión de la enzima óxido nítrico sintetasa inducible (iNOS), tanto en las células circulantes positivas para el virus como en las infectadas in vitro, al compararse con controles sanos y células no infectadas (62).

Se ha evaluado el efecto de los factores solubles producidos por estas células monocíticas activadas sobre las células endoteliales de microvasculatura humana (HMVEC), como por ejemplo las THP-1 infectadas con DENV-2, que redujeron la resistencia eléctrica transendotelial, lo que se interpreta como una menor integridad del endotelio y una mayor permeabilidad endotelial (70). Este daño de las células endoteliales también se ha observado en un sistema transwell en el que se ponen en contacto células HUVEC con sobrenadantes de monocitos primarios infectados con DENV-2 para evaluar el paso de la proteína peroxidasa de rábano picante conjugada con estreptavidina (71). Todo esto sugiere que la infección in vitro e in vivo con DENV induce la activación de los monocitos, con la consecuente producción de mediadores inflamatorios que pueden aportar en gran medida a la tormenta de citoquinas y al compromiso vascular visto en esta enfermedad (Figura 1).

Los monocitos humanos circulantes se pueden dividir en tres subpoblaciones de acuerdo a la expresión del receptor de membrana del lipopolisacarido (LPS) CD14 y del CD16, un FcyR de baja afinidad (FcrRIII), isoforma A. Teniendo en cuenta lo anterior se pueden encontrar los monocitos clásicos (CD14++CD16-), los no clásicos (CD14+CD16++) y los intermedios $(C D 14++C D 16+)$ (72). En individuos sanos, la subpoblación de monocitos clásicos se encuentra en mayor porcentaje (80-90 \%) respecto a los no clásicos (10-15 \%) y los intermedios (1-5 \%) (73). Los monocitos clásicos e intermedios se caracterizan por la expresión de los receptores de quimioquinas CCR2 y CCR5 con niveles bajos de CX3CR1, que contrastan con los monocitos no clásicos, los cuales tienen menor expresión de CCR2 y de CCR5, pero sí grandes cantidades de CX3CR1 (74). También se ha descrito que los monocitos clásicos al estimularse con LPS producen principalmente IL-10 y pocas cantidades de TNF- $\alpha$, además de expresar más receptores scavenger (barrenderos o pepenadores) en comparacion con las otras dos supoblaciones. Estas células tienen una mayor interacción con el endotelio de macrovasculatura $(56,73-76)$. Por otra parte, los monocitos no clásicos son los principales productores de TNF- $\alpha$ frente a la estimulación con LPS, poseen una mayor expresión de TLRs comparados con los clásicos, por lo que se consideran los más proinflamatorios. Esto se ha demostrado en algunos modelos de enfermedades infecciosas como la tuberculosis; dichas células, además, son las encargadas de la vigilancia y homeostasis del endotelio de microvasculatura $(56,73-76)$. Los monocitos intermedios producen baja cantidad de IL-10 y de TNF- $\alpha$ frente a la estimulación con LPS en comparacion con los monocitos clásicos y no clásicos, respectivamente, expresan más HLA-DR y al parecer no interactúan con células endoteliales (56, 73-76).

Aún se desconoce en gran medida el papel que desempeñan estas subpoblaciones de monocitos dentro de la inmunopatología del dengue y en su gravedad. No obstante, teniendo en cuenta que los monocitos no clásicos son una fuente importante de TNF- $\alpha$, entre otros factores proinflamatorios (77), además de que son los que interactúan preferiblemente con céIulas endoteliales de microvasculatura (78), es posible proponer que estos fagocitos deben tener un papel importante en la inmunopatología de la enfermedad (Tabla 1 y Figura 1). En el año 2010, Azeredo et aI., encontraron una mayor expresión de CD16 en los monocitos de pacientes con dengue durante la fase febril de la enfermedad, así como con la infección in vitro de monocitos de individuos sanos con DENV-2 (69). Adicionalmente, observaron mayores porcentajes de la subpoblación intermedia en los pacientes con las formas moderadas (definido como conteo de plaquetas por encima de $100000 / \mathrm{mm}^{3}$ sin hipotensión, $12 \%$ ) $y$ graves (definido como conteo de plaquetas por debajo de $100000 / \mathrm{mm}^{3}$ con hipotensión $8 \%$ ) de la enfermedad comparados con los controles sanos (5\%); también se encontró una disminución de la subpoblación clásica en los casos moderados (56 \%) y severos (65\%) en contraste con los sanos (77\%) (69) (Tabla 1). 
Tabla 1. Subpoblaciones de monocitos en pacientes con dengue y la respuesta de estos fagocitos en DENV

\begin{tabular}{|c|c|c|c|c|c|}
\hline & $\begin{array}{c}\text { Clásicos } \\
\text { CD14++CD16- }\end{array}$ & $\begin{array}{c}\text { Intermedios } \\
\text { CD14++CD16+ }\end{array}$ & $\begin{array}{l}\text { No clásicos } \\
\text { CD14+CD16++ }\end{array}$ & $\begin{array}{l}\text { Tipo de } \\
\text { ensayo }\end{array}$ & Referencia \\
\hline $\begin{array}{l}\text { Frecuencia comparada } \\
\text { con los controles sanos }\end{array}$ & $\downarrow$ & $\uparrow$ & $\downarrow$ & Ex vivo & $(64,69,79,80)$ \\
\hline $\begin{array}{l}\text { CD68 extracelular, CD69, TNF-a, } \\
\text { externalización de PS* }\end{array}$ & $\downarrow$ & $\downarrow$ & $\uparrow$ & Ex vivo & (79) \\
\hline$\%$ de monocitos NS1+ & $5-10 \%$ & \multicolumn{2}{|c|}{$5-10 \%$} & In vitro & (77) \\
\hline$\%$ de monocitos proteína viral E+ & $0,5 \%-4 \%$ & \multicolumn{2}{|c|}{$0,5 \%-4 \%$} & In vitro & (77) \\
\hline $\begin{array}{l}\text { Unidades formadoras } \\
\text { de placa } \times 10^{4} / \mathrm{ml}\end{array}$ & $0-7$ & \multicolumn{2}{|c|}{$0-7$} & In vitro & (77) \\
\hline IFN-a, CXCL-10 y TRAIL* & $=$ & \multicolumn{2}{|c|}{$=$} & In vitro & (77) \\
\hline IL-1 $\beta$, TNF- $\alpha$, IL-6, CCL2, CCL3 y CCL4* & $\downarrow$ & \multicolumn{2}{|c|}{$\uparrow$} & In vitro & (77) \\
\hline iNOS* & $\uparrow$ & \multicolumn{2}{|c|}{$\downarrow$} & Ex vivo & (80) \\
\hline IDO* & $\downarrow$ & \multicolumn{2}{|c|}{$\uparrow$} & Ex vivo & (80) \\
\hline
\end{tabular}

IFN- $\alpha$ : interferon alfa; TRAIL: ligando inductor de apoptosis relacionado con el factor de necrosis tumoral; IL: interleuquina; TNF- $\alpha$ : Factor de necrosis tumoral alfa; PS: Fosfatidilserina; iNOS: sintasa de óxido nítrico inducible; IDO: indolamina 2 3-dioxigenasa. *Resultados comparando entre las subpoblaciones de monocitos.

Mediante la infección in vitro con DENV-2 de las subpoblaciones de monocitos CD14+ (tanto CD16+ como CD16-) obtenidas a partir de sangre periférica de individuos sanos, Wong et al., (77) observaron una susceptibilidad similar a la infección y unos niveles de producción de los factores antivirales IFN- $\alpha$, CXCL10 y TRAIL, comparables entre ambas subpoblaciones (Figura 1).

Además, se encontró que los monocitos CD16+ secretaron más TNF $\alpha$, IL-1 $\beta$, IL-6, y quimioquinas del tipo CCL-2 y CCL-4 en respuesta a la infección (Figura 1). Los autores sugirieron que la subpoblación no clásica, posiblemente, está međiando una actividad más protectora que podría estar asociada, en parte, con un reclutamiento de células hacia el tejido infectado. Teniendo en cuenta estos resultados y que el TNF $\alpha$ y el CCL2 están relacionados con la permeabilidad vascular $(50,51)$, esta subpoblación no clásica podría estar contribuyendo preferencialmente con la tormenta de citoquinas además de estar participando en la alteración del endotelio observada en los pacientes con formas graves de dengue. De hecho, nosotros hemos obervado que son los monocitos no clásicos los que presentan una mayor expresión de marcadores de activación como por ejemplo CD69, CD68 extracelular, un mayor porcentaje de células TNF $\alpha+y$ que han externalizado la fosfatidilserina (PS+) en pacientes infectados con dengue, al compararlos con las otras subpoblaciones de monocitos y con controles sanos (79) (Tabla 1 y Figura 1).

Kwissa et aI. (64) observaron por citometría de flujo un aumento estadísticamente significativo del porcentaje de monocitos a expensas de la subpoblación intermedia, en los estadios agudos de la enfermedad en humanos y primates no humanos infectados con DENV-2. En estos últimos, se observó un claro aumento de los monocitos intermedios circulantes en los días 1-3 postinfección y se encontró un número alto de estos monocitos intermedios en los nódulos linfáticos drenantes al tercer día (Tabla 1). Además, mediante un cocultivo observaron que la subpoblación de monocitos intermedios infectados con DENV-2 indujo la diferenciación de células $B$ autólogas a plasmablastos productores de IgM, de forma dependiente de las citoquinas BAFF, APRIL e IL-10; sugiriendo que la infección por DENV produce un aumento de los monocitos intermedios, los cuales promueven la diferenciación de las células B a plasmablastos, lo que podría llevar a un aumento de anticuerpos de baja afinidad contra el virus.

El aumento en plasmablastos $y$ anticuerpos de baja afinidad se ha descrito previamente en pacientes con dengue (81), lo que al parecer podría promover el incremento en la carga viral del individuo por medio de $\mathrm{ADE}$, incluso desde infecciones primarias (64). 


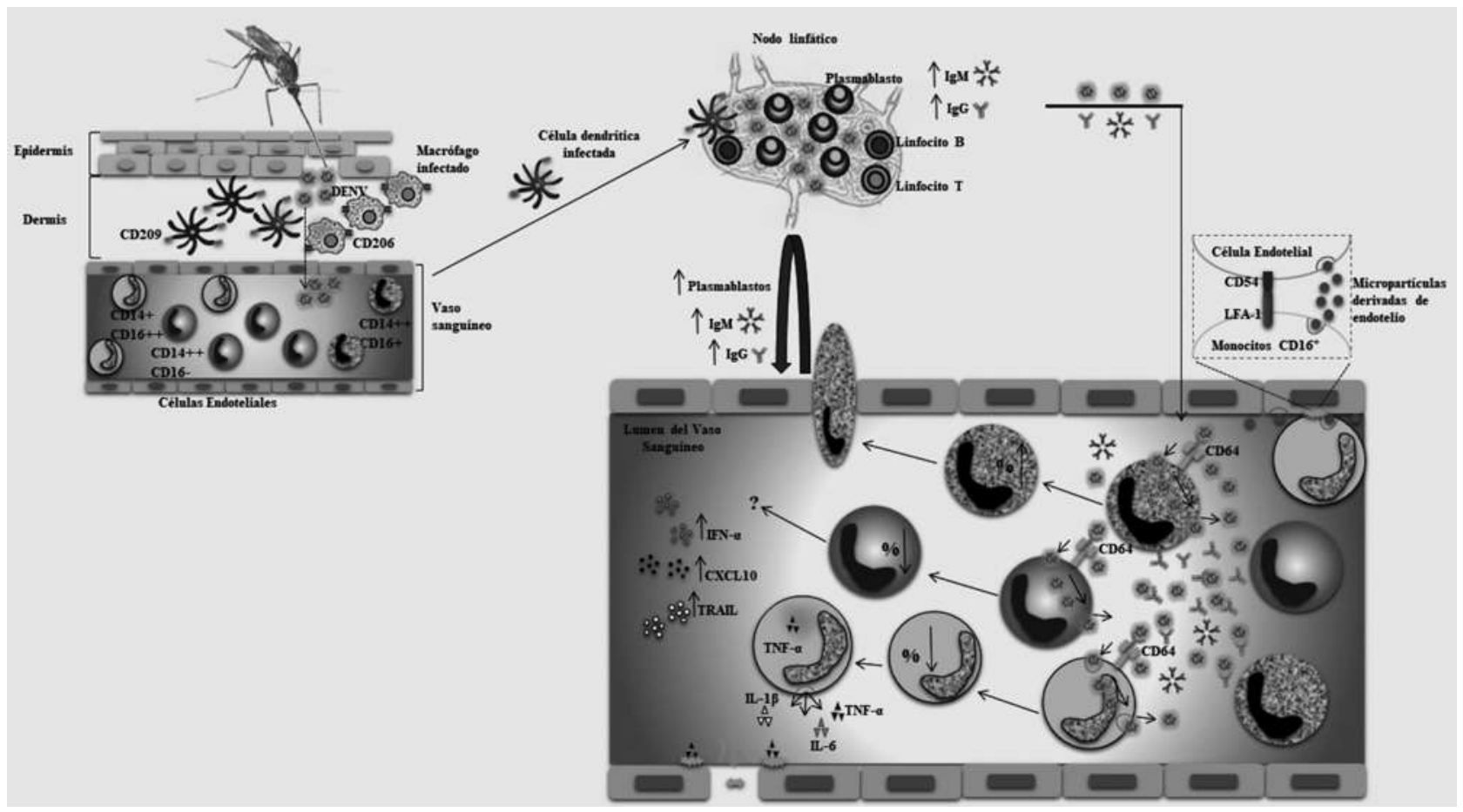

Figura 1. Potencial participación de las subpoblaciones de monocitos en la inmupatología del dengue. El virus ingresa por via cutánea interactuando inicialmente con células residentes de la dermis (29,31-33); posteriormente se produce la replicación viral y la producción de anticuerpos en los nódulos linfáticos, generando un aumento tanto de los viriones como de los niveles de $\lg M$ e $\lg G$ en la sangre (81); una vez en el torrente sanguíneo, el virus dengue interactúa principalmente con los monocitos $(60,77)$, provocando la disminución en el porcentaje de la supoblacion clásica (CD14++CD16-), junto con un aumento de la subpoblación intermedia (CD14++CD16+), la cual esta asociada a una retroalimentación positiva en la producción de plasmablastos y con esto un incremento en los niveles de anticuerpos, pontenciando posibles procesos de ADE (64). Además se produce la disminución de la subpoblación no clásica (CD14+CD16++), que tiene como función basal la vigilancia del endotelio (76), y son las células que contribuyen principalmente con la produccion de citoquinas proinflamatorias asociadas a la disrupción de la integridad endotelial frente al virus dengue $(64,67,69,77,79,80)$

Por último, en un estudio realizado recientemente en pacientes infectados con DENV-4 provenientes de Brazil, se encontró que la expresión de la iNOS fue mayor en los monocitos CD16- comparados con los monocitos $\mathrm{CD} 16+$, mientras que estos últimos tuvieron mayor expresión de la indolamina 2 y 3-dioxigenasa (IDO) (Tabla 1). Sugiriendo que, si bien ambas clases de monocitos se activan en respuesta a la infección, la presencia de iNOS debe estar ayudando a controlar el virus en los monocitos clásicos, mientras que los bajos niveles de esta enzima en los monocitos CD16+, así como el aumento en IDO, sugieren que estas células podrían estar promoviendo la generación de Linfocitos T reguladores en el contexto de la infección y, posiblemente, promoviendo la diseminación viral (80).
Además, también es poco lo que se conoce del papel de las subpoblaciones de monocitos en otras infecciones virales. Por ejemplo, se ha observado en pacientes con VIH-1 un aumento en la frecuencia de los monocitos intermedios con infección aguda, con un aumento en su expression de HLA-DR al compararse con controles sanos. También se observó una disminución en la frecuencia de los monocitos clásicos en estos pacientes. Los monocitos no clásicos, por su parte, solo se encontraron disminuidos en los pacientes con infección crónica (82). Los monocitos clásicos humanos expuestos a los virus de sarampión y herpes simplex tipo I produjeron altos niveles de IL-6 e IL-8, mientras que los no clásicos secretaron una baja cantidad de estas citoquinas, pero niveles significativamente mayores de 
TNF $\alpha-$, IL- $1 \beta$ y CCL3 en respuesta a estos virus, por una vía dependiente de TLR-7, TLR-8 y MyD88 (78).

\section{CONCLUSIONES Y PERSPECTIVAS}

Las evidencias recopiladas en esta revisión dejan claro que los monocitos tienen un papel protagónico, pero dual, en la infección por DENV. Participan en el control de la viremia gracias a la produccion de factores antivirales como el IFN- $\alpha$, pero también tienen un papel importante en el desarrollo de la infección, al ser una de las principales células blanco. Esto, junto con la alta capacidad que tienen estos fagocitos de producir citoquinas proinflamatorias frente a la infeccion por DENV, permite concluir su importancia durante la inmunopatología de la enfermedad y su potencial papel en la tormenta de citoquinas, el aumento en la permeabilidad endotelial $y$, finalmente, en el desarrollo del dengue grave.

Por otro lado, los pocos estudios que existen sobre las subpoblaciones de monocitos en la inmunopatología del dengue, apuntan a que existe un papel diferencial de cada subpoblación (Tabla 1 y Figura 1). Teniendo en cuenta las diferencias funcionales $y$ fenotípicas que poseen estas células de forma basal, así como en diferentes modelos inflamatorios e infecciosos, es muy probable que cada subpoblación de monocitos tenga una respuesta y un papel contrastante frente a la infección por el DENV (Figura 1). Por ejemplo, la subpoblación no clásica encargada de la vigilancia y mantenimiento de la homeostasis del endotelio, se propone como un elemento crucial en el desarrollo de las manifestaciones graves de la enfermedad, por aportar de forma considerable a la producción de citoquinas proinflamatorias como el TNF- $\alpha$ y la IL- $1 \beta$ en respuesta al DENV (77). Esto resalta la importancia de hacer más estudios en este campo, ya que un mayor entendimiento de la contribución de estas células en la respuesta inmune contra el dengue podría llevar a identificar nuevos y tempranos blancos terapéuticos, que conduzcan a menor desarrollo de signos de alarma y manifestaciones graves de la enfermedad.

\section{AGRADECIMIENTOS}

Agradecemos a COLCIENCIAS (proyecto 111556933247) y Universidad de Antioquia (Sostenibilidad, Sistema Universitario de Investigaciones, CODI) por financiar nuestro trabajo. Agradecemos a los profesores Mauricio Rojas, Silvio Urcuqui-Inchima (Universidad de Antioquia) y Berta Nelly Restrepo (Instituto Colombiano de Medicina Tropical) por la lectura crítica del manuscrito.

\section{CONFLICTOS DE INTERESES}

Ninguno por declarar.

\section{REFERENCIAS BIBLIOGRÁFICAS}

1. Manning AK, Hivert MF, Scott RA, Grimsby JL, Bouatia-Naji N, Chen H, et al. A genome-wide approach accounting for body mass index identifies genetic variants influencing fasting glycemic traits and insulin resistance. Nat Genet. 2012 May;44(6):659-69. DOI $10.1038 / \mathrm{ng} .2274$.

2. HalsteadSB. Dengue.Lancet. 2007 Nov;370(9599):164452.

3. Martina BE, Koraka P, Osterhaus AD. Dengue virus pathogenesis: an integrated view. Clin Microbiol Rev. 2009 Oct;22(4):564-81. DOI 10.1128/CMR.00035-09.

4. Mustafa MS, Rasotgi $\nabla$, Jain S, Gupta $\nabla$. Discovery of fifth serotype of dengue virus (DENV-5): A new public health dilemma in dengue control. Med J Armed Forces India. 2015 Jan; 71(1):67-70. DOI 10.1016/j.mjafi.2014.09.011.

5. World Health Organization, Special Programme for Research and Training in Tropical Diseases. Dengue: Guidelines for Diagnosis, Treatment, Prevention and Control: New Edition [Internet]. WHO: Geneva; 2009. Available from: https://apps.who.int/iris/bitstream/handle/10665/44188/9789241547871_eng.pdf;jsessionid $=79 \mathrm{~F}$ 41776AED688B322813DBD0A37024B? sequence $=1$.

6. Gould EA, Solomon T. Pathogenic flaviviruses. Lancet. 2008 Feb;371(9611):500-9. DOI 10.1016/S01406736(08)60238-X.

7. Guzman MG, Halstead SB, Artsob H, Buchy P, Farrar J, Gubler DJ, et aI. Dengue: a continuing global threat. Nat Rev Microbiol. 2010 Dec;8(12 Suppl):S7-16. DOI $10.1038 /$ nrmicro2460.

8. Bhatt S, Gething PW, Brady OJ, Messina JP, Farlow AW, Moyes CL, et al. The global distribution and burden of dengue. Nature. 2013 Apr;496(7446):504-7. DOI 10.1038/nature 12060 . 
9. Guzman MG, Harris E. Dengue. Lancet. 2015 Jan;385(9966):453-65. DOI 10.1016/S0140-6736(14)60572-9.

10. Shepard DS, Undurraga EA, Halasa YA. Economic and disease burden of dengue in Southeast Asia. PLoS Negl Trop Dis. 2013;7(2):e2055. DOI 10.1371/ journal.pntd.0002055.

11. Boletin Epidemiologico semanal. Instituto Nacional de Salud; 2017:1-30. https://www.ins.gov.co/buscador-eventos/BoletinEpidemiologico/2017\%20Bolet\%C3\%ADn\%20 epidemiol\%C3\%B3gico\%20semana\%2052.pdf.

12. Diamond MS, Pierson TC. Molecular Insight into Dengue Virus Pathogenesis and Its Implications for Disease Control. Cell. 2015 Jul;162(3):488-92. DOI 10.1016/j. cell.2015.07.005.

13. Rodenhuis-Zybert IA, Wilschut J, Smit JM. Dengue virus life cycle: viral and host factors modulating infectivity. Cell Mol Life Sci. 2010 Aug;67(16):2773-86. DOI 10.1007/s00018-010-0357-z.

14. Screaton G, Mongkolsapaya J, Yacoub S, Roberts C. New insights into the immunopathology and control of dengue virus infection. Nat Rev Immunol. 2015 Dec;15(12):745-59. DOI 10.1038/nri3916.

15. St John AL, Abraham SN, Gubler DJ. Barriers to preclinical investigations of anti-dengue immunity and dengue pathogenesis. Nat Rev Microbiol. 2013 Jun;11(6):420-6. DOI 10.1038/nrmicro3030.

16. Cruz-Oliveira C, Freire JM, Conceição TM, Higa LM, Castanho MA, Da Poian AT. Receptors and routes of dengue virus entry into the host cells. FEMS Microbiol Rev. 2015 Mar;39(2):155-70. DOI 10.1093/femsre/fuu004.

17. Guzman MG, Alvarez M, Halstead SB. Secondary infection as a risk factor for dengue hemorrhagic fever/dengue shock syndrome: an historical perspective and role of antibody-dependent enhancement of infection. Arch Virol. 2013 Jul;158(7):1445-59. DOI 10.1007/s00705-013-1645-3.

18. Modis Y, Ogata S, Clements D, Harrison SC. Structure of the dengue virus envelope protein after membrane fusion. Nature. 2004 Jan;427(6972):313-9.

19. Modis Y. Relating structure to evolution in class II viral membrane fusion proteins. Curr Opin Virol. 2014 Apr;5:34-41. DOI 10.1016/j.coviro.2014.01.009.

20. Fernandez-Garcia MD, Mazzon M, Jacobs M, Amara A. Pathogenesis of flavivirus infections: using and abusing the host cell. Cell Host Microbe. 2009 Apr;5(4):318-28. DOI 10.1016/j.chom.2009.04.001.
21. Mangada MM, Endy TP, Nisalak A, Chunsuttiwat S, Vaughn DW, Libraty DH, et al. Dengue-specific T cell responses in peripheral blood mononuclear cells obtained prior to secondary dengue virus infections in Thai schoolchildren. J Infect Dis. 2002 Jun; 185(12):1697-703.

22. Zmurko J, Neyts J, Dallmeier K. Flaviviral NS4b, chameleon and jack-in-the-box roles in viral replication and pathogenesis, and a molecular target for antiviral intervention. Rev Med Virol. 2015 Jul;25(4):205-23. DOI $10.1002 / \mathrm{rm} \nabla .1835$.

23. Bressanelli S, Stiasny K, Allison SL, Stura EA, Duquerroy S, Lescar J, et al. Structure of a flavivirus envelope glycoprotein in its low-pH-induced membrane fusion conformation. EMBO J. 2004 Feb;23(4):728-38.

24. Sampath A, Padmanabhan R. Molecular targets for flavivirus drug discovery. Antiviral Res. 2009 Jan;81(1):6-15. DOI 10.1016/j.antiviral.2008.08.004.

25. Ackermann M, Padmanabhan R. De novo synthesis of RNA by the dengue virus RNA-dependent RNA polymerase exhibits temperature dependence at the initiation but not elongation phase. J Biol Chem. 2001 Oct;276(43):39926-37.

26. Egloff MP, Benarroch D, Selisko B, Romette JL, Canard B. An RNA cap (nucleoside-2'-O-)-methyltransferase in the flavivirus RNA polymerase NS5: crystal structure and functional characterization. EMBO J. 2002 Jun;21(11):2757-68.

27. Guyatt KJ, Westaway EG, Khromykh AA. Expression and purification of enzymatically active recombinant RNA-dependent RNA polymerase (NS5) of the flavivirus Kunjin. J Virol Methods. 2001 Mar;92(1):37-44.

28. Modhiran N, Watterson D, Muller DA, Panetta AK, Sester DP, Liu L, et al. Dengue virus NS1 protein activates cells via Toll-like receptor 4 and disrupts endothelial cell monolayer integrity. Sci Transl Med. 2015 Sep;7(304):304ra142. DOI 10.1126/scitransImed. aaa3863.

29. Wu SJ, Grouard-Vogel G, Sun W, Mascola JR, Brachtel E, Putvatana R, et al. Human skin Langerhans cells are targets of dengue virus infection. Nat Med. 2000 Jul;6(7):816-20.

30. St John AL, Rathore AP, Yap H, Ng ML, Metcalfe DD, Vasudevan SG, et al. Immune surveillance by mast cells during dengue infection promotes natural killer (NK) and NKT-cell recruitment and viral clearance. 
Proc Natl Acad Sci U S A. 2011 May;108(22):9190-5. DOI 10.1073/pnas.1105079108.

31. Tassaneetrithep B, Burgess TH, Granelli-Piperno A, Trumpfheller C, Finke J, Sun W, et al. DC-SIGN (CD209) mediates dengue virus infection of human dendritic cells. J Exp Med. 2003 Apr;197(7):823-9.

32. Miller JL, de Wet BJ, Martinez-Pomares L, Radcliffe CM, Dwek RA, Rudd PM, et al. The mannose receptor mediates dengue virus infection of macrophages. PLoS Pathog. 2008 Feb;4(2):e17. DOI 10.1371/journal. ppat.0040017.

33. Schmid MA, Harris E. Monocyte recruitment to the dermis and differentiation to dendritic cells increases the targets for dengue virus replication. PLoS Pathog. 2014 Dec;10(12):e1004541. DOI 10.1371/journal. ppat. 1004541 .

34. Lin YW, Wang KJ, Lei HY, Lin YS, Yeh TM, Liu HS, et aI. Virus replication and cytokine production in dengue virus-infected human B lymphocytes. J Virol. 2002 Dec;76(23): 12242-9.

35. Jessie K, Fong MY, Devi S, Lam SK, Wong KT. Localization of dengue virus in naturally infected human tissues, by immunohistochemistry and in situ hybridization. J Infect Dis. 2004 Apr 15;189(8):1411-8.

36. Arévalo MT, Simpson-Haidaris PJ, Kou Z, Schlesinger JJ, Jin X. Primary human endothelial cells support direct but not antibody-dependent enhancement of dengue viral infection. J Med Virol. 2009 Mar;81(3):519-28. DOI 10.1002/jmv.21408.

37. Blackley S, Kou Z, Chen H, Quinn M, Rose RC, Schlesinger JJ, et al. Primary human splenic macrophages, but not $\mathrm{T}$ or $\mathrm{B}$ cells, are the principal target cells for dengue virus infection in vitro. J Virol. 2007 Dec;81(24):13325-34.

38. de Macedo FC, Nicol AF, Cooper LD, Yearsley M, Pires AR, Nuovo GJ. Histologic, viral, and molecular correlates of dengue fever infection of the liver using highly sensitive immunohistochemistry. Diagn Mol Pathol. 2006 Dec; 15(4):223-8.

39. Tsai YT, Chang SY, Lee CN, Kao CL. Human TLR3 recognizes dengue virus and modulates viral replication in vitro. Cell Microbiol. 2009 Apr;11(4):604-15. DOI 10.1111/j.1462-5822.2008.01277.x.

40. Castillo Ramirez JA, Urcuqui-Inchima S. Dengue Virus Control of Type I IFN Responses: A History of Manipulation and Control. J Interferon Cytokine Res. 2015 Jun;35(6):421-30. DOI 10.1089/jir.2014.0129.
41. Perdomo-Celis F, Salgado DM, Narváez CF. Selective dysfunction of subsets of peripheral blood mononuclear cells during pediatric dengue and its relationship with clinical outcome. Virology. 2017 Jul;507:1119. DOI 10.1016/j.virol.2017.04.004.

42. Starnes T, Robertson MJ, Sledge G, Kelich S, Nakshatri H, Broxmeyer HE, et al. Cutting edge: IL-17F, a novel cytokine selectively expressed in activated $\mathrm{T}$ cells and monocytes, regulates angiogenesis and endothelial cell cytokine production. J Immunol. 2001 Oct; 167(8):4137-40.

43. Moi ML, Takasaki T, Saijo M, Kurane I. Dengue virus infection-enhancing activity of undiluted sera obtained from patients with secondary dengue virus infection. Trans R Soc Trop Med Hyg. 2013 Jan; 107(1):51-8. DOI 10.1093/trstmh/trs007.

44. Balsitis SJ, Williams KL, Lachica R, Flores D, Kyle JL, Mehihop E, et al. Lethal antibody enhancement of dengue disease in mice is prevented by Fc modification. PLoS Pathog. 2010 Feb;6(2):e1000790. DOI 10.1371/journal.ppat. 1000790.

45. Hatch S, Endy TP, Thomas S, Mathew A, Potts J, Pazoles $\mathrm{P}$, et al. Intracellular cytokine production by dengue virus-specific T cells correlates with subclinical secondary infection. J Infect Dis. 2011 May;203(9):128291. DOI 10.1093/infdis/jiro12.

46. Rathakrishnan A, Wang SM, Hu Y, Khan AM, Ponnampalavanar S, Lum LC, et al. Cytokine expression profile of dengue patients at different phases of illness. PLoS One. 2012;7(12):e52215. DOI 10.1371/journal. pone.0052215.

47. Cruz Hernández SI, Puerta-Guardo HN, Flores Aguilar H, González Mateos S,López Martinez I, Ortiz-Navarrete $\nabla$, et al. Primary dengue virus infections induce differential cytokine production in Mexican patients. Mem Inst Oswaldo Cruz. 2016 Mar;111(3):161-7. DOI 10.1590/0074-02760150359.

48. Espada-Murao LA, Morita K. Dengue and soluble mediators of the innate immune system. Trop Med Health. 2011 Dec;39(4 Suppl):53-62. DOI 10.2149/ tmh.2011-S06.

49. Atrasheuskaya A, Petzelbauer P, Fredeking TM, Ignatyer G. Anti-TNF antibody treatment reduces mortality in experimental dengue virus infection. FEMS Immunol Med Microbiol. 2003 Jan;35(1):33-42.

50. Dewi BE, Takasaki T, Kurane I. Peripheral blood mononuclear cells increase the permeability of dengue 
virus-infected endothelial cells in association with downregulation of vascular endothelial cadherin. J Gen Virol. 2008 Mar;89(Pt 3):642-52. DOI 10.1099/ vir.0.83356-0.

51. Appanna R, Wang SM, Ponnampalavanar SA, Lum LC, Sekaran SD. Cytokine factors present in dengue patient sera induces alterations of junctional proteins in human endothelial cells. Am J Trop Med Hyg. 2012 Nov;87(5):936-42. DOI 10.4269/ajtmh.2012.11-0606.

52. Jeewandara C, Gomes L, Wickramasinghe N, Gutowska-Owsiak D, Waithe D, Paranavitane SA, et al. Platelet activating factor contributes to vascular leak in acute dengue infection. PLoS Negl Trop Dis. 2015 Feb;9(2):e0003459. DOI 10.1371/journal. pntd.0003459.

53. Souza DG, Fagundes CT, Sousa LP, Amaral FA, Souza RS, Souza AL, et al. Essential role of platelet-activating factor receptor in the pathogenesis of Dengue virus infection. Proc Natl Acad Sci U S A. 2009 Aug;106(33):14138-43. DOI 10.1073/pnas.0906467106.

54. Malavige GN, Ogg GS. Pathogenesis of vascular leak in dengue virus infection. Immunology. 2017 Jul;151(3):261-9. DOI 10.1111/imm.12748.

55. Vervaeke P, Vermeire K, Liekens S. Endothelial dysfunction in dengue virus pathology. Rev Med Virol. 2015 Jan;25(1):50-67. DOI 10.1002/rmv.1818.

56. Ginhoux F, Jung S. Monocytes and macrophages: developmental pathways and tissue homeostasis. Nat Rev Immunol. 2014 Jun;14(6):392-404. DOI 10.1038/nri3671.

57. Auffray C, Sieweke MH, Geissmann F. Blood monocytes: development, heterogeneity, and relationship with dendritic cells. Annu Rev Immunol. 2009;27:66992. DOI 10.1146/annurev.immunol.021908.132557.

58. Auffray C, Fogg D, Garfa M, Elain G, Join-Lambert O, Kayal S, et al. Monitoring of blood vessels and tissues by a population of monocytes with patrolling behavior. Science. 2007 Aug;317(5838):666-70.

59. Strauss-Ayali D, Conrad SM, Mosser DM. Monocyte subpopulations and their differentiation patterns during infection. J Leukoc Biol. 2007 Aug;82(2):244-52.

60. Kou Z, Quinn M, Chen H, Rodrigo WW, Rose RC, Schlesinger JJ, et al. Monocytes, but not T or B cells, are the principal target cells for dengue virus (DV) infection among human peripheral blood mononuclear cells. J Med Virol. 2008 Jan;80(1):134-46.
61. Durbin AP, Vargas MJ, Wanionek K, Hammond SN, Gordon A, Rocha C, et al. Phenotyping of peripheral blood mononuclear cells during acute dengue illness demonstrates infection and increased activation of monocytes in severe cases compared to classic dengue fever. Virology. 2008 Jul;376(2):429-35. DOI 10.1016/j.virol.2008.03.028.

62. Neves-Souza PC, Azeredo EL, Zagne SM, Valls-deSouza R, Reis SR, Cerqueira DI, et al. Inducible nitric oxide synthase (iNOS) expression in monocytes during acute Dengue Fever in patients and during in vitro infection. BMC Infect Dis. 2005 Aug;5:64.

63. Perdomo-Celis F, Salgado DM, Narváez CF. Magnitude of viremia, antigenemia and infection of circulating monocytes in children with mild and severe dengue. Acta Trop. 2017 Mar;167:1-8. DOI 10.1016/j.actatropica.2016.12.011.

64. Kwissa M, Nakaya HI, Onlamoon N, Wrammert J, Villinger F, Perng GC, et al. Dengue virus infection induces expansion of a CD14(+)CD16(+) monocyte population that stimulates plasmablast differentiation. Cell Host Microbe. 2014 Jul;16(1):115-27. DOI 10.1016/j.chom.2014.06.001.

65. Espina LM, Valero NJ, Hernández JM, Mosquera JA. Increased apoptosis and expression of tumor necrosis factor-alpha caused by infection of cultured human monocytes with dengue virus. Am J Trop Med Hyg. 2003 Jan;68(1):48-53.

66. Bosch I, Xhaja K, Estevez L, Raines G, Melichar H, Warke RV, et al. Increased production of interleukin-8 in primary human monocytes and in human epithelial and endothelial cell lines after dengue virus challenge. J Virol. 2002 Jun;76(11):5588-97.

67. Perdomo-Celis F, Romero F, Salgado DM, Vega R, Rodríguez J, Angel J, et al. Identification and Characterization at the Single-Cell Level of Cytokine-Producing Circulating Cells in Children With Dengue. J Infect Dis. 2018 Apr;217(9):1472-80. DOI 10.1093/infdis/jiy053.

68. Chunhakan S, Butthep P, Yoksan S, Tangnararatchakit K, Chuansumrit A. Vascular leakage in dengue hemorrhagic Fever is associated with dengue infected monocytes, monocyte activation/exhaustion, and cytokines production. Int J Vasc Med. 2015;2015:917143. DOI 10.1155/2015/917143.

69. Azeredo EL, Neves-Souza PC, Alvarenga AR, Reis SR, Torrentes-Carvalho A, Zagne SM, et al. Differential regulation of toll-like receptor-2, toll-like receptor-4, 
CD16 and human leucocyte antigen-DR on peripheral blood monocytes during mild and severe dengue fever. Immunology. 2010 Jun;130(2):202-16. DOI 10.1111/j.1365-2567.2009.03224.x.

70. Kelley JF, Kaufusi PH, Nerurkar VR. Dengue hemorrhagic fever-associated immunomediators induced via maturation of dengue virus nonstructural $4 \mathrm{~B}$ protein in monocytes modulate endothelial cell adhesion molecules and human microvascular endothelial cells permeability. Virology. 2012 Jan;422(2):326-37. DOI 10.1016/j.virol.2011.10.030.

71. Lee YR, Liu MT, Lei HY, Liu CC, Wu JM, Tung YC, et al. MCP-1, a highly expressed chemokine in dengue haemorrhagic fever/dengue shock syndrome patients, may cause permeability change, possibly through reduced tight junctions of vascular endothelium cells. J Gen Virol. 2006 Dec;87(Pt 12):3623-30.

72. Yona S, Jung S. Monocytes: subsets, origins, fates and functions. Curr Opin Hematol. 2010 Jan;17(1):53-9. DOI 10.1097/MOH.0b013e3283324f80.

73. Ziegler-Heitbrock L, Hofer TP. Toward a refined definition of monocyte subsets. Front Immunol. 2013 Feb;4:23. DOi 10.3389/fimmu.2013.00023.

74. Wong KL, Tai JJ, Wong WC, Han H, Sem X, Yeap WH, et al. Gene expression profiling reveals the defining features of the classical, intermediate, and nonclassical human monocyte subsets. Blood. 2011 Aug; 1 18(5):e16-31. DOI 10.1182/blood-2010-12-326355.

75. Boyette LB, Macedo C, Hadi K, Elinoff BD, Walters JT, Ramaswami B, et al. Phenotype, function, and differentiation potential of human monocyte subsets. PLoS One. 2017 Apr;12(4):e0176460. DOI 10.1371/ journal.pone. 0176460 .

76. Atehortúa L, Rojas M, Vásquez GM, Castaño D. Endothelial Alterations in Systemic Lupus Erythematosus and Rheumatoid Arthritis: Potential Effect of Monocyte Interaction. Mediators Inflamm. 2017;2017:9680729. DOI 10.1155/2017/9680729.

77. Wong KL, Chen W, Balakrishnan T, Toh YX, Fink K, Wong SC. Susceptibility and response of human blood monocyte subsets to primary dengue virus infection. PLoS One. 2012;7(5):e36435. DOI 10.1371/ journal.pone.0036435.

78. Cros J, Cagnard N, Woollard K, Patey N, Zhang SY, Senechal B, et al. Human CD14dim monocytes patrol and sense nucleic acids and viruses via TLR7 and TLR8 receptors. Immunity. 2010 Sep;33(3):375-86. DOI 10.1016/j.immuni.2010.08.012.

79. Naranjo-Gomez JS, Castillo JA, Rojas M, Restrepo BN, Diaz FJ, Velilla PA, et al. Different phenotypes of non-classical monocytes associated with systemic inflammation, endothelial alteration and hepatic compromise in patients with dengue. Immunology. 2019 Feb;156(2):147-63. DOI 10.1111/imm.13011.

80. Fialho LG, Torrentes-Carvalho A, Cunha RV, Faria $\mathrm{N}$, Gandini $M$, Cipitelli $M$, et al. Induced nitric oxide synthase (iNOS) and indoleamine 2,3-dioxygenase (IDO) detection in circulating monocyte subsets from Brazilian patients with Dengue-4 virus. Virology Reports. 2017 Jun;7:9-19. DOI 10.1016/j.virep.2017.02.001.

81. Wrammert J, Onlamoon N, Akondy RS, Perng GC, Polsrila K, Chandele A, et al. Rapid and massive virus-specific plasmablast responses during acute dengue virus infection in humans. J Virol. 2012 Mar;86(6):2911-8. DOI 10.1128/JVI.06075-11.

82. Chen P, Su B, Zhang T, Zhu X, Xia W, Fu X, et al. Perturbations of Monocyte Subsets and Their Association with T Helper Cell Differentiation in Acute and Chronic HIV-1-Infected Patients. Front Immunol. 2017 Mar;8:272. DOI 10.3389/fimmu.2017.00272. 